\title{
REFLEXÕES SOBRE CORPO E SUA EDUCABILIDADE
}

\author{
Patricia Carlesso Marcelino ${ }^{1}$ \\ Eldon Henrique Muhl²
}

\section{Resumo}

O corpo e sua educabilidade é um dos desafios mais importantes no contexto das sociedades plurais e complexas. O texto propõe-se refletir sobre as características que marcam a relação com o corpo na atualidade e as exigências que se estabelecem para que se possa desenvolver uma concepção de corporeidade que, pela educação, desenvolvam o reconhecimento e a dignificação da corporeidade de cada indivíduo. Essas inquietações emergem de práticas docentes cotidianas em diferentes contextos formativos em que diversas constatações sobre o papel e o sentido do corpo revelam visões reducionistas e limitadoras, tanto no trato quanto nas concepções dos educandos sobre seu próprio corpo e o corpo do outro.

Palavras-chave: Educação. Corpo. Emoções. Corporeidade. Sociedades Plurais e Complexas.

\section{REFLECTIONS ON THE BODY AND ITS EDUCABILITY}

\begin{abstract}
The body and its educability is one of the most important challenges in the context of plural and complex societies. The text proposes to reflect on the characteristics that mark the relation with the body in the present time and the requirements that are established so that a conception of corporeity can be developed that, through education, develops the recognition and dignification of the corporeity of each individual. These concerns emerge from everyday teaching practices in different formative contexts in which various findings on the role and sense of the body reveal reductive and limiting views both in the tract and in the students' conceptions of their own body and the body of the other.
\end{abstract}

Keywords: Education. Body. Emotions. Corporeity. Plural and Complex Societies.

\footnotetext{
1 Doutora e Mestre em Educação pela Universidade de Passo Fundo-RS; Especialista em Docência na Saúde (UFRGS); Especialista em Atividade física e Qualidade de Vida (UPF);Licenciada Plena em Educação Física (UPF); Docente Universitária, Arteterapeuta e Personal Wellness; patriciacarlessowellness@gmail.com

2 Pós-Doutor pela Universidade do Minho, Portugal, Licenciado em Filosofia e Doutor em Filosofia e História da Educação pela Universidade de Campinas, Orientador e docente no PPGEDU-UPF; eldon@upf.br
} 


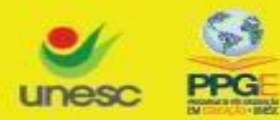

Criar Educação, Criciúma, v. 9, no2, Edição Especial 2020.- PPGE - UNESC - ISSN 2317-2452

\section{Introdução}

O presente texto tem como objetivo explorar a possibilidade de compreender a educação do corpo como uma importante ferramenta para a formação humana , com base nos estudos e encontros do grupo de pesquisa "Teoria e Prática na Formação do Educador: Exigências e Desafios da Prática Pedagógica na Sociedade Complexa e Plural" da Universidade de Passo Fundo (UPF) - RS, como também é um tema basilar da investigação de minha tese de Doutorado, em andamento, pelo PPGEDUUPF na qual abordará sobre a formação e educação do corpo e "seu uso".

O corpo é um tema particularmente propicio a uma análise crítica no campo educacional, pois ele é certamente o principal elemento identificador da condição do homem no mundo e o mais importante fator de determinação da concepção de cada indivíduo sobre si mesmo e sobre os outros. Sem o corpo o homem não existiria e a presença diante de si mesmo e dos outros não passaria de uma miragem. Graças ao corpo nos tornamos presença no mundo e é nele que desenvolvemos nossa identidade.

A concepção predominante de corpo na história da Filosofia é a que destaca sua função como instrumento da alma e é a partir desta concepção, que se mostra para González e Fensterseifer (2006,p.99 )em diferentes pensadores, assumindo distintas tonalidades ao longo da História ocidental. Tal é a perspectiva que prevalece na filosofia helênica representada pela obra platônica, como se expressa em Fédon, bem como na obra de Aristóteles "Metafísica". Esta concepção, ainda que, com outras características, vai aparecer na obra de Epicuro daquele mesmo período e, especialmente do helenismo dos estóicos, os quais afirmavam ser a alma que domina o corpo, num reducionismo que o considera orgânico e físico.

Abbagnano (2000) esclarece que esta doutrina da instrumentalidade irá preponderar na concepção de corpo presente na Filosofia do período medieval, enquanto na modernidade, por meio do cérebro, passa a ser caracterizado, em especial a partir dos partidários do materialismo vulgar, como produtor da alma, 


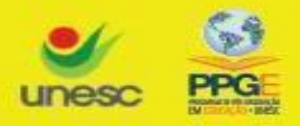

Criar Educação, Criciúma, v. 9, no22, Edição Especial 2020.- PPGE - UNESC - ISSN 2317-2452

mantendo em última instância, o mesmo esquema explicativo de instrumento para algo.

Talvez, em função desta secundarização que o corpo sofreu ao longo da História ocidental a partir do século $X X$, tenha se transformado em foco de interesse das ciências sociais e das humanas, e de acordo com González e Fensterseifer (2006) que passam a problematizar, ainda que, parcialmente, os diferentes tipos de dualismo que o consideram como mero substrato biológico ou um dado exclusivamente natural.

Com base nessas premissas iniciais, nos propomos a refletir sobre as concepções e práticas que delimitam as relações do corpo na atualidade, identificando as exigências, os padrões e os procedimentos práticos que envolvem a corporeidade e suas relações com os processos formativos, tanto nos contextos formais como informais. Trata-se de analisar o quanto o corpo é considerado como fator central da formação da condição humana e da vida social.

Se a questão que envolve a presença do corpo como base da condição humana é incontestável, já não podemos dizer o mesmo quando se trata de avaliar a importância do corpo e a necessidade de seu desenvolvimento saudável nos discursos e nas práticas educativas. Existe uma polissemia nos discursos que tratam do corpo, e em muitos momentos esquece-se da materialidade do corpo e de sua existência carnal, dificultando a compreensão do sentido efetivo que ele tem para a constituição da condição humana e do seu papel na formação da identidade de cada indivíduo.

Entendemos, portanto, que a compreensão e as práticas corporais podem traduzir, revelar e evidenciar formas bem precisas de educação e formas múltiplas de socialização. As referências aos copos e a educação são inúmeras, como são inúmeras também as maneiras de pensar os corpos, sua vitalidade, seu acontecer, suas dores, seus prazeres, seus limites e suas potencialidades. As diversas formas de representação e de práticas corporais revelam os diferentes comportamentos e as diferentes atitudes que os indivíduos manifestam em relação ao corpo. 
Registrar e refletir sobre essas formas e manifestações múltiplas sobre o corpo e a suas singularidades é o que pretendemos com este texto. Em síntese, procuramos analisar de que maneira o processo educativo hoje predominante influência na educabilidade do corpo e na formação das compreensões sobre o sentido e o significado da corporeidade.

González e Fensterseifer (2006, p.103) conceituam corporeidade numa definição ampla como uma idéia abstrata de corpo, de ser corpóreo. Este sentido é herança do pensamento grego, expresso no conceito de soma ou somático. Para os gregos, soma designa o que é material, especialmente no homem, em oposição a psique ou psíquico. As culturas latinas e cristãs reforçaram esta significação ao entender a corporalista como aquilo que é de natureza material ou, simplesmente, materialidade, radicalidade oposta à espiritualidade. Nesse sentido, portanto, corporeidade diz respeito a tudo que é material, porque todo ser material se manifestada como corpo.

\section{Corporeidade, condição humana e formação}

Viver consiste em um constante voltar-se para seu corpo e para o corpo dos outros. Le Breton (2016) reforça que a existência é corporal. Os tratamentos sociais e culturais de que o corpo é objeto, as imagens que the expõem a espessura escondida, os valores que o distinguem, falam-nos também da pessoa e das variações que sua definição e seus modos de existência conhecem, de uma estrutura social a outra.Porquanto está no cerne da ação individual e coletiva, no cerne do simbolismo social, o corpo é um objeto de análise de grande alcance para melhor apreensão do presente

O corpo não possui uma objetividade que se define por si mesmo. Cada sociedade, no interior de sua visão de mundo, delineia um conceber sobre o corpo e sobre a corporeidade: seu sentido, seus elementos constitutivos, suas performances, suas correspondências. As diferentes sociedades e os diferentes momentos históricos 


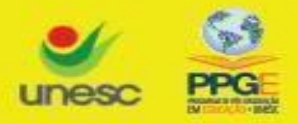

Criar Educação, Criciúma, v. 9, no2, Edição Especial 2020.- PPGE - UNESC - ISSN 2317-2452

conferem sentidos e valores diferenciados ao corpo. Isso leva os indivíduos a terem concepções diferentes sobre seu próprio corpo e o corpo do outro.

Sant'Anna (2000, p.56) enfatiza que o corpo, em particular, não cessa de ser coagido a funcionar como um processador comunicacional ambulante, sendo que ele sempre funcionou como uma mídia, mas atualmente essa condição parece ter merecido um destaque inusitado. Como que somente agora, ligado às novas tecnologias, ele exercesse plenamente essa função. A ênfase na necessidade de tornar tudo comunicável, passível de entrar em relação, não deixa, contudo, de provocar suspeitas, talvez ela seja apenas resultado da dificuldade de encontrar mensagens de fato importantes. De todo modo, ela exprime a atual vontade de tornar objetos e corpos mais sensíveis.

Assim, para exemplificar, podemos identificar na história do pensamento humano a existência de grupos sociais que não separam a condição de cada ser humano do seu corpo, ao contrário da visão hegemônica predominante na cultura ocidental que apresenta uma visão dualista do ser humano, em que o corpo é secundário em relação à alma. O corpo é visto como perecível e fonte dos muitos males que se fazem presente no mundo enquanto a alma, fonte das virtudes e do bem, é imortal. A identidade do indivíduo, nesta concepção, se vincula à alma e a negação da importância do corpo.

Nas sociedades tradicionais o corpo não se distingue da pessoa. As matériasprimas que compõem a espessura do homem são as mesmas que dão consistência ao cosmos e à natureza. Nesse sentido, Le Breton (2016,p.09) evidencia que entre o homem, o mundo e os outros, um mesmo estofo reina com motivos e cores diferentes, os quais não modificam em nada a trama comum .

Ao longo da história humana uma herança educativa e cultural permeada de representações, normativas, estigmas e tabus, as quais se misturam de forma simbiótica com nossa identidade. Temas contemporâneos como a sexualidade e a corporeidade ainda causam grandes polêmicas e discussões entre a sociedade, 


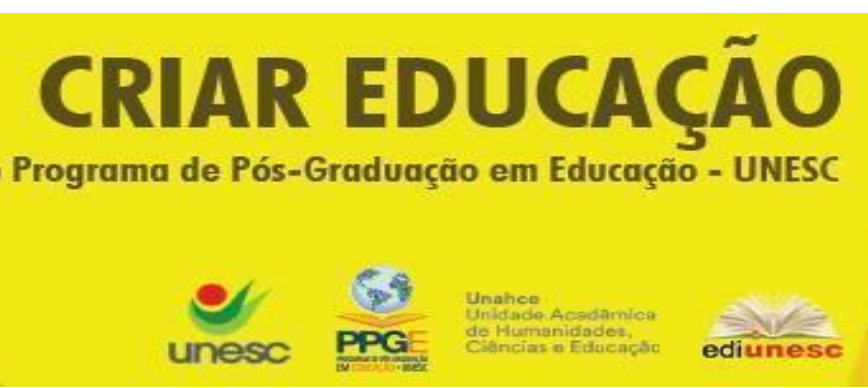

Criar Educação, Criciúma, v. 9, no22, Edição Especial 2020.- PPGE - UNESC - ISSN 2317-2452

também, nos contextos educativos e entre os meios de comunicação, bem como nas mídias sociais.

Mendes e Nóbrega (2004, p.125) apontam que a educação ainda recebe fortes influências do pensamento cartesiano que, através de uma visão dualista, tem como fundamentos axiomas matemáticos, ordem e leis da mecânica. O corpo humano, ao ser comparado com uma máquina hidráulica, recebe uma educação que o considera apenas em seu aspecto mecânico, sem vontade própria, sem desejos e sem 0 reconhecimento da intencionalidade do movimento humano, o qual é explicado através de uma mera reação de estímulos externos, sem qualquer subjetividade.

O processo formativo, vivenciado necessariamente por todos os seres humanos, pode ser mais ou menos intencional e estruturado, dependendo do contexto, do grau de racionalização da sociedade e do nível de desenvolvimento dos grupos sociais. Encontramos, na história da humanidade, diversos exemplos do modo mediante o qual as sociedades, em diferentes contextos, organizaram processos formativos de modo que seus novos membros assimilassem a herança cultural, os costumes e os valores que eram fundamentais ao desenvolvimento de cada um deles e à manutenção dessas comunidades. A Paidéia e a Bildung são exemplos desse esforço por institucionalizar um projeto formativo com 0 alcance global (SILVA, 2016, p.49).

Nesse sentido, Cenci e Marcon (2016) sinalizam que as sociedades complexas características. Os modos de vida das crianças, assim como dos adultos, são marcados pelas agudas e permanentes transformações que os envolvem. Com o avanço do mercado de bens simbólicos e a difusão maciça da informação, ocorridos na metade do século $X X$, surge uma nova configuração sociocultural e com ela, a cultura de massa com forte acento socializador.

A complexificação social é impulsionada pela tecnologia digital e, com ela, pela introdução cada vez mais ampliada de novos dispositivos tecnológicos, os quais são manuseados intensamente pelas novas gerações. Não há dúvida de que essa nova situação social acentua a crise das formas $s$ tradicionais de autoridade, contudo, esse é o aspecto mais preocupante da complexificação social, no sentido desordenado dos dispositivos digitais, significa também o questionamento sobre qualquer tipo de autoridade, principalmente daquele que as gerações mais velhas exercem sobre as mais novas (DALBOSCO; CASAGRANDA, 2016,p.69). 


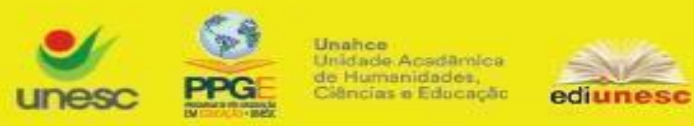

Criar Educação, Criciúma, v. 9, no2, Edição Especial 2020.- PPGE - UNESC - ISSN 2317-2452

Dalbosco e Casagranda ainda nos dizem que o pêndulo parece ter se curvado inteiramente para o outro lado: a sociedade complexa vive sob o domínio e os ditames das novas gerações, sobretudo da tirania que a criança, movida pelas leis da sociedade consumista e sua parafernália tecnológica, exerce sobre o adulto.Nesse sentido, visualizam também, em seu ponto de vista, a crise da autoridade tradicional e conservadora, os pais, professores e religiosos que continua teimando em fazer valer a qualquer custo a autoridade, produzem um discurso vazio, de pouco efeito formativo-educacional.

A moderna tecnologia, para $\operatorname{Vaz}$ (2006,p.28), faz com que o homem contemporâneo vive numa relação dependente, acentuada de experiências pobres de vivência corporal e motriz. A poderosa indústria dos meios de comunicação, ao mesmo tempo em que traz ao homem inúmeras possibilidades de aquisição de conhecimentos e novas perspectivas, afasta-o de experiências sensíveis imediatas com o mundo que o cerca.

A modernização sociopolítica e tecnológica, um processo dinâmico pelo qual o mundo atual vem passando, coloca desafios inéditos; desafios que exigem além de inovações tecnológicas e científicas também a revisão de formas de sociabilidade e a reorganização de suas instituições. Nesse contexto, de acordo com Flickinger (2016) o sistema educativo é visto como área importante da reação a esses desafios. $O$ autor ainda cita que o espaço pedagógico não escapa à acelerada complexificação de suas tarefas e se vê obrigado a buscar maneiras efetivas no seu manejo. As decisões sobre o rumo das políticas educativas enfrentam um leque amplo de fatores.

Trata-se então não apenas de novas demandas externas e fora do alcance dos profissionais da área, senão também da necessidade de dar conta delas mediante a reestruturação interna do campo profissional e institucional. A complexidade crescente do espaço pedagógico resulta, portanto, de sua reestruturação interna para assimilar novos fatores externos. 


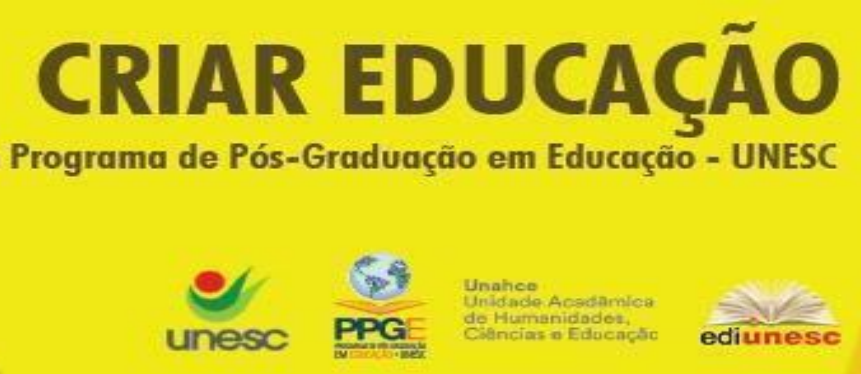

Criar Educação, Criciúma, v. 9, no2, Edição Especial 2020.- PPGE - UNESC - ISSN 2317-2452

Outro aspecto, este citado por Georgen (2016, p.29) está relacionado ao conceito de sociedade plural ${ }^{1}$, o qual anda de passo com outros conceitos, tais como os de globalização, multiculturalismo e cosmopolítica, ora de grande evidência, mas já presentes na nossa história pregressa. $\mathrm{O}$ autor sinaliza que na sociedade global e plural interconectada pelos meios de comunicação e pela mobilidade social, o risco de o ser humano se transformar num ser genérico, sem individualidades, sem seus caracteres individuais e singulares, chama cada vez mais a atenção de sociólogos, psicólogos, antropólogos e pedagogos. Devido à crescente influência e confluência de diferentes culturas, visões de mundo e concepções éticas, torna-se vital encontrar caminhos para o processo formativo em termos de políticas públicas, de conteúdos e procedimentos pedagógicos.

Nesse sentido Gonçalves ( 1999 ) enfatiza que os diversos acontecimentos e contextos históricos que permearam a ação humana na era industrial, e que se relacionam com sua corporeidade, apontam para um processo de "descorporalização"(Entkoerperlichung) do homem. O conceito de descorporalização, segundo a autora significa, por um lado, que, ao longo do processo de civilização, em uma evolução contínua de racionalização, o homem foi tornando-se, progressivamente, o mais independente possível da comunicação empática do seu corpo com o mundo, reduzindo a capacidade de percepção sensorial e aprendendo, simultaneamente, a controlar seus afetos e emoções, transformando a livre manifestação de seus sentimentos em expressões e gestos formalizados. A crescente diferenciação de funções na sociedade e, consequentemente, o crescimento da

\footnotetext{
${ }^{1}$ Sociedade plural não é outra coisa senão esse panorama da humanidade multicultural, ou seja, o cenário de confluência e miscigenação em que as incongruências entre costumes, valores, tradições, ideais, visões de mundo e convicções religiosas entram em contato e confronto na luta por espaços, poder e domínio. O grande desafio que se coloca, então é a harmonização entre, de um lado, o direito á identidade cultural com tudo que isso importa, e, de outro, a necessidade de convivência, do respeito e do reconhecimento das identidades culturais entre si. Esse é o desafio da contemporaneidade que ora se despende da colonização essencialista para ingressar numa nova cultura da convivência de culturas com base no entendimento e reconhecimento. (GEORGEN,2016, p.38).
} 


\title{
CRIAR EDUCAÇÃO \\ Revista do Programa de Pós-Graduação em Educação - UNESC
}

Criar Educação, Criciúma, v. 9, no2, Edição Especial 2020.- PPGE - UNESC - ISSN 2317-2452

interdependência entre as pessoas geraram uma teia de entrelaçamentos funcionais e institucionais, na qual o indivíduo é cada vez mais ameaçado em sua existência social, necessitando por isso, prever, calcular os efeitos de suas ações e reações sobre os outros, aprendendo a reprimir seus afetos e a postergar a satisfação de suas necessidades...

\begin{abstract}
As necessidades na sociedade industrial, crescem constantemente e expandem-se, o homem perde de vista os fins de sua ação e, ante as permanentes ameaças que enfrenta, reprime suas necessidades e, com isso, sua chance de satisfação e gratificação. Acompanhando o processo de civilização, crescem o planejamento e o cálculo, incompatíveis com a espontaneidade e ações imediatas a impulsos. No trabalho, a manipulação do corpo, foi, progressivamente, assumindo proporções cada vez mais graves, com a expansão do sistema capitalista e com o desenvolvimento da tecnologia: os movimentos corporais tornaram-se instrumentalizados, como se pode observar, por exemplo na indústria, ao dissociar os movimentos corporais em partes isoladas para aumentar a produção. O mesmo acontece no esporte institucionalizado, no qual persistem as ideias de uma ilimitada manipulação e aperfeiçoamento do corpo e de uma quantificação das capacidades corporais (GONÇALVES,1999, p.17).
\end{abstract}

Como diz Mounier apud Vaz, (2006), os moles prazeres do conforto foram progressivamente substituindo as paixões da aventura, e o bem mecânico, impessoal, distribuidor de um prazer regular, sem excesso nem perigo, o prazer da conquista. As criações de uma civilização que enveredou pelas vias da facilidade inumana fabricam cada vez mais a "inércia tranquila", que traz consigo pobreza de movimentos e de experiências sensoriais, coopera também com a organização do espaço físico das grandes cidades, que impede o homem de um contato maior com a natureza e reduz sua vida de movimentos e ações estereotipadas e mecanizadas em locais predeterminados. E, assim, à medida em que as atividades do homem procuram desligá-lo da participação corporal, vai perdendo sua ligação viva e afetiva com a natureza e o mundo social.

De acordo com o pensar de Georgen (2016) que nos diz que , a expansão da territorialidade pelo rompimento das fronteiras geográficas, culturais, étnicas e grupais, pelos novos mecanismos de comunicação com a veiculação de valores e ideais poluídos de individualismo, pragmatismo, egoísmo, utilitarismo e o 


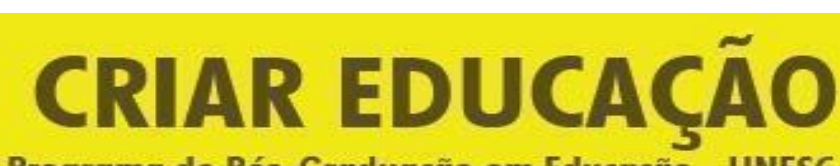

Revista do Programa de Pós-Graduação em Educação - UNESC
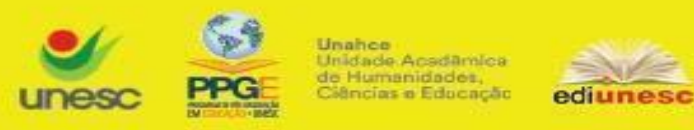

Criar Educação, Criciúma, v. 9, no2, Edição Especial 2020.- PPGE - UNESC - ISSN 2317-2452

mercadorismo interfere diretamente na ordem do formativo .As dimensões epistêmica, ética e estética, nucleares ao processo formativo, são formuladas a partir dos interesses sistêmicos da ordem econômica globalizada. [...] O sistema impõe se forma violenta sobre a vida cotidiana forçando a todos a se adaptar e a responder. $\mathrm{O}$ dinheiro, a tecnologia e a informação invadem e intoxicam o espaço da subjetividade no qual deveria ocorrer o processo formativo. Efeito externo gera tal "fatalidade" contemporânea, quando os indivíduos incorporam o responder e o adaptar-se como o sentido máximo de sua perfectibilidade formativa.

A cultura, para Georgen (2016, p.37), pode ser definida como um processo de intercâmbio entre indivíduos, grupos e sociedades no seu empenho pela vida e sobrevivência. A própria cultura passa a ser entendida como um processo em movimento. $O$ indivíduo, na dinâmica de aculturação, não se insere num contexto cultural homogêneo e fixo, como ocorria no passado; ele se a cultura numa sociedade envolta em tríplice movimento: a sociedade plural, a sociedade global e a sociedade em devir.

Nesse devir, em si desconcertado, a permanência, sempre frágil e provisória, mas essencial à vida humana, inscreve-se no âmbito da criatividade crítica do agir comunicativo. Nestes termos, a permanência emerge no e do devir por obra do argumento humano ancorado nos princípios de justiça social, democracia e respeito à pluralidade.

\section{A educabilidade do corpo e das emoções}

A educação é condição essencial ao processo de humanização dos indivíduos e à existência das sociedades, e para Marques (1996) somente nos tornamos humanos no sentido estrito do termo, à medida que nos socializamos, adentramos numa cultura e nos individualizamos por meio do processo de aprendizagem e de formação.Por isso, podemos dizer que a educação consiste em um fenômeno 
primordial e básico da vida humana, congênere e contemporâneo da própria vida em todas as suas fases e situações.

Ao longo da história humana uma herança educativa e cultural permeada de representações, normativas, estigmas e tabus, as quais se misturam de forma simbiótica com nossa identidade. Temas contemporâneos como a sexualidade e a corporeidade ainda causam grandes polêmicas e discussões entre a sociedade, a escola e nos meios de comunicação.

Nussbaum (2008, p.183) nos diz que as sociedades divergem em suas crenças metafísicas, religiosas e cosmológicas. Em todas as culturas as práticas educativas estabelecem ao menos algumas distinções entre meninos e meninas, embora o grau e natureza de tais diferenças variam entre culturas e indivíduos.

A forma de a escola controlar e disciplinar o corpo, de acordo com Vaz (2006, p. 33) está ligada aos mecanismos das estruturas de poder, resultantes do processo histórico da civilização ocidental. As práticas escolares tendem a perpetuar a forma de internalização das relações do homem com o mundo, que consiste na supervalorização das operações cognitivas e no progressivo distanciamento da experiência sensorial direta. A escola nos últimos 150 anos de processo civilizatório pretende não somente disciplinar o corpo e, com ele, os sentimentos, as ideias e as lembranças a ele associadas, como também, por vezes anulá-lo.

Os processos educativos sofreram uma série de transformações, em especial as que se vinculam ao corpo e a corporeidade: outrora sendo extremamente fechada, modelizada (tendo o corpo ideal idealizado pela mídia, pelo trabalho produtivo ou pela moda, e não pela saúde integral), sendo extremamente estigmatizada, e, por outro lado aberta, expositiva, vendável...

Foucault (1984; 1999; 2003), em seus estudos históricos, relata como se efetivava o poder disciplinar sobre o corpo e as escolas do século XVIII e XIX. As escolas eram, então, como fábricas, que produziam disposições para ações racionais voluntárias, ao mesmo tempo que procuravam eliminar dos corpos movimentos 


\title{
CRIAR EDUCAÇÃO \\ Revista do Programa de Pós-Graduação em Educação - UNESC
}

Criar Educação, Criciúma, v. 9, no2, Edição Especial 2020.- PPGE - UNESC - ISSN 2317-2452

incompleta frente a proporções do mundo que controlamos e tais evoluções, abordam sobre o temor, a esperança, a aflição, a ira e o amor...

Assim, desatentos e deseducados, nossos sentidos vão se obliterando, enquanto na crença de que o único conhecimento importante é o caráter abstrato do nosso cérebro, um cérebro que não só pensa e realiza cálculos sem se dar conta do modo sensível ao derredor (DUARTE JUNIOR, 2006, p.100).

Duarte Junior (2006) defende que o mundo hoje desestimula qualquer refinamento dos sentidos humanos e promove a sua deseducação, levando-nos a regredir a níveis toscos e grosseiros:

\begin{abstract}
Nossas casas não expressam mais afeto e aconchego, temerosa e apressadamente nossos passos cruzam perigosos espaços de cidades polidas, nossas conversas são estritamente profissionais e, na maioria das vezes, mediadas por equipamentos eletrônicos, nossa alimentação, feita às pressas e de modo automático, entope-nos de alimentos insossos, contaminados e modificados industrialmente, nossas mãos já não manipulam elementos da natureza, espigões de concreto ocultam horizontes, os odores que comumentemente sentimos, provém de canos de descarga automotivos, trabalhamos de maneira mecânica e desprazerosa até o estresse (DUARTE JUNIOR,2006,p.18).
\end{abstract}

A corporeidade é mais do que uma mera aparência ou embalagem do homem, é a própria constituição e configuração material e simbólica do nosso ser no mundo. Identificamo-nos como corpo quando nos tornamos consciência de nossa individualidade, ao deixarmos de nos confundir com o meio ou com o outro, passando a perceber o limite entre o eu, o outro e o meio.

Também o fazemos, quando ocorre o processo de identificação com o outro, ao percebermos que somos, também, em muitos aspectos, iguais ou semelhantes aos outros. Assim, num processo, ao mesmo tempo, de socialização e de individualização, reconhecemos de alguma forma, ainda que não verbalizada, que tempo radicalmente semelhantes e ao mesmo tempo diferentes em relação a todo e qualquer ser humano.

A pele, o corpo, conforme afirma Le Breton (2010), envolve os próprios limites, estabelece a fronteira entre o dentro e o fora de maneira vívida, porosa, pois ela 


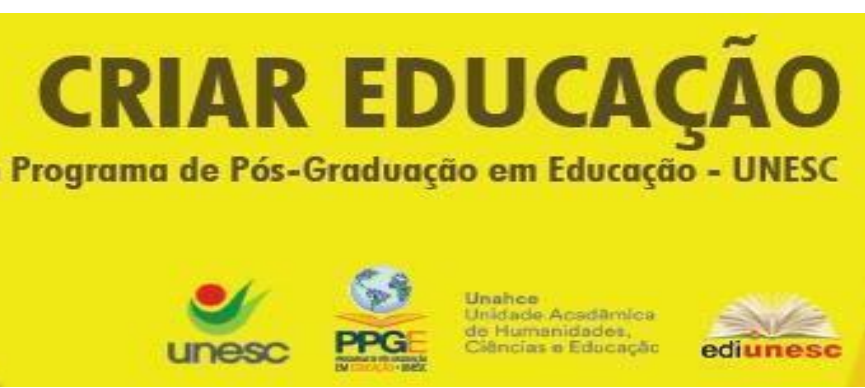

Criar Educação, Criciúma, v. 9, no2, Edição Especial 2020.- PPGE - UNESC - ISSN 2317-2452

também é uma abertura para o mundo, uma memória viva. É um termômetro do gosto pela vida. Ela envolve e incorpora a pessoa distinguindo-a dos demais. É uma tela onde projetamos uma identidade sonhada, como no caso da tatuagem, do piercing ou das inúmeras maneiras de encenar a aparência que regem as nossas sociedades. Ou pelo contrário, ela encarcera em uma identidade insuportável da qual desejamos abdicar, tendo como testemunha as lesões corporais deliberadas.

A pele é uma instância de manutenção do psiquismo, isto é, de enraizamento do sentimento de si dentro de um corpo que individualiza. Ela também exerce uma função de contenção, ou seja, de amortecimento das tensões que vêm de fora e de dentro. Fronteira que protege contra a agressão externa ou contra a tensão íntima, dá ao indivíduo a sensação dos limites de significado que o autorizam a sentir-se tomado por sua existência, ou à deriva do caos e da vulnerabilidade.

A relação com o mundo de cada homem é, para Le Breton (2016), portanto, uma questão de pele, e de solidez ou não da sua função de contenção. Não estar bem em sua pele implica algumas vezes a reorganização de sua superfície, para vestir uma nova pele e nela melhor se encontrar. As marcas corporais são balizas da identidade, são formas de inscrever limites na pele, e não apenas, enquanto metáfora. "A pele participa intensamente no processo de separação-individuação que caracteriza a passagem do adolescente." .

As pessoas imersas em determinados universos simbólicos e culturais, de
um lado, necessitam partilhar símbolos, conceitos, valores, ideais, imagens
de mundo como elementos norteadores de sua formação; de outro, precisam
rejeitar para preservar sua autonomia e liberdade. A formação significa o
tenso movimento entre o ouvir e ser ouvido; rejeitar e ser rejeitado; influenciar
e ser influenciado; reconhecer e ser reconhecido. (GEORGEN, 2016, p.35).

As ritualizações íntimas participam da superação da barreira do sofrimento e desenham uma área de transição onde se emaranham a experiência emocional e o processo de simbolização. São constantemente, resistências imediatas, ou exibidas ao longo do tempo, diante do mal-estar experimentado. Maneira de curvar-se e ou de 
levantar-se diante da emoção ou da situação "sem se quebrar", de manifestar uma forma de esquiva eficaz, que evita a ruptura, as condutas de risco permitem um enfrentamento, são comportamentos de ajuste a uma situação pessoal dolorosa.

Em pleno século XXI percebemos seus nuances e resquícios, modelados em uma nova forma de ver o corpo: o que se vincula através da comunicação, das redes sociais, da exposição corporal, das mídias vendáveis, que o utilizam para potencializar seus lucros, e de outro o da vigilância permitida: das câmeras de monitoramento que cerceiam os contextos laborais, residenciais e educacionais, muitas vezes não permitindo uma comunicação saudável, natural com as pessoas em seus entornos e também limitando-se a movimentos restritos, robotizados, que não expressam sua corporeidade.

Georgen (2016) por fim, sinaliza que, no movimento polarizado e persistente entre os pólos antinômicos desses binômios, realiza-se a formação humana, tanto em ambientes formais quanto informais de educação. O aporte novo, próprio das sociedades plurais e complexas, é o caráter instável e plural deste universo formativo. Perde-se a permanência e a fixidez que conferiram autoridade e legitimidade aos processos formativos tradicionais em que objetivos claros e socialmente referenciados justificavam os procedimentos impositivos usados para "transmitir" conhecimentos e posturas éticas vinculantes a serem incorporados com resignação e conformismo. A escola, é um lugar de socialização em que essas diferenças aparecem de forma mais significativa, exigindo posturas de entendimento e reconhecimento.

Para compreendermos essas aproximações que se adensam sob os impulsos e mecanismos de mobilidade e comunicação e alcançarmos uma efetiva compreensão do outro, Georgen sinaliza que há uma longa e difícil travessia de ida ao outro e de retorno a si mesmo num movimento de superação das barreiras conceituais, éticas e perceptivas...O fio condutor desta postura é a sempre renovada pergunta a respeito do que são e do que devem ser o homem, a sociedade e o mundo. Para isso, precisamos restituir a ágora como espaço de reconhecimento, dignidade, justiça, diálogo de todos com iguais e diferentes. Diálogo significa reconhecer as 
razões dos outros, integrando-as na conversa, na busca do valor universal do humano, aberto às diferenças e circunstâncias humanas. A humanidade muito mais que uma essência a ser consagrada, é uma construção do pensar conjunto e articulado no contexto de um mundo plural de racionalidades, éticas e estéticas.

\section{À guisa de (in) conclusão...}

A forma de o homem lidar com sua corporeidade, os regulamentos, normativas e o controle do comportamento corporal não são universais e constantes, mas, sim, uma construção social, resultante de um contexto histórico. O homem ao viver em um determinado contexto social interage de forma dinâmica, pois ao mesmo tempo em que atua com a realidade, modificando-a, esta atua sobre ele, influenciando e, até podemos dizer, direcionando suas formas de pensar, sentir e agir. Assim, as concepções que o homem desenvolve a respeito de sua corporeidade estão ligadas a condicionamentos sociais e culturais.

A cultura exprime suas marcas no indivíduo, ditando normas e fixando idéias, nas dimensões intelectuais, afetiva, moral e física, ideais esses indicam à Educação, o que deve ser alcançado no processo de socialização. O corpo de cada indivíduo de um grupo cultural revela, assim, não somente sua singularidade pessoal, mas também tudo o que caracteriza esse grupo social singular e complexo.

Nesse sentido considera-se de suma importância continuar a refletir e discutir esse cabedal de provocações/ insinuações que os meios de comunicação produzem acerca das questões vinculadas ao corpo, a sexualidade, a saúde ao processo educacional e cultural, sendo necessária se pensar a corporeidade numa perspectiva mais responsável, mais natural, tendo em vista as necessidades e características humanas vigentes com vistas ao bem-estar, a saúde e a cidadania, tendo em vista as grandes transformações sociais e toda sua complexidade delas decorrentes. 


\section{REFERÊNCIAS}

ABBAGNANO, N. Dicionário Critico de Filosofia. In: GONZÁLEZ, Jaime; FENSTERSEIFER, Paulo Evaldo. (orgs.). Dicionário Critico de Educação Física. ljuí: Editora UNIJUI,2006.

CASAGRANDE, Cledes Antonio. Nadja Hermann e os Contornos de uma Autêntica Filosofia da Educação no Brasil. In: RAJOBAC, Raimundo; BOMBASSARO, Luiz Carlos; GEORGEN, Pedro. Experiência Formativa e Reflexão. Caxias do Sul: EDUCS,2016.

CENCI, Angelo Vitório; MARCON, Telmo.Sociedades Complexas e Desafios educativos: indvidualização, socialização e democracia. In: MÜHL, Eldon Henrique; DALBOSCO, Claudio Almir; CENCI, Angelo Vitório. (Orgs). Questões Atuais da Educação - Sociedade Complexa, Pensamento Pós-Metafísico, Democracia e Formação Humana. ljui: Editora UNIJUI, 2016.

DALBOSCO, Claudio Almir; CASAGRANDA, Edison Alencar. Educação em Sociedades Tradicionais e Sociedades Complexas: o problema da crise de autoridade. In: MÜHL, Eldon Henrique; DALBOSCO, Claudio Almir; CENCl, Angelo Vitório. (Orgs). Questões Atuais da Educação - Sociedade Complexa, Pensamento Pós-Metafísico, Democracia e Formação Humana. Ijui: Editora UNIJUI, 2016.

DUARTE JUNIOR, João Francisco. O sentido dos sentidos: a educação (do)sensível. 4.ed. Curitiba: Criar Edições,2006.

FOUCAULT, Michel. Vigiar e Punir: nascimento da prisão. 3. ed. Petropolis: Vozes,1984.

A história da sexualidade I: a vontade de saber. 13. ed. Rio de Janeiro: Graal, 1999.

Microfísica do poder.18. ed. Rio de Janeiro: Graal, 2003.

FLICKINGER, Hans-Georg. A Educação Diante da Complexidade da Sociedade contemporânea. In: MÜHL, Eldon Henrique; DALBOSCO, Claudio Almir; CENCI, 


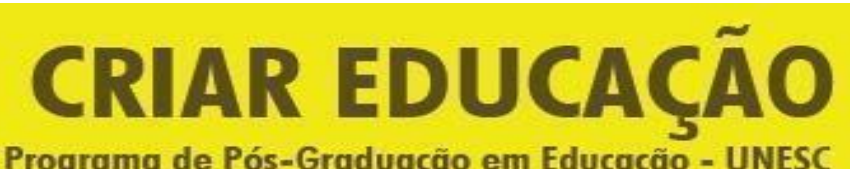

Revista do Programa de Pós-Graduação em Educação - UNESC

Criar Educação, Criciúma, v. 9, №2, Edição Especial 2020.- PPGE - UNESC - ISSN 2317-2452

Angelo Vitório. (Orgs). Questões Atuais da Educação - Sociedade Complexa, Pensamento Pós-Metafísico, Democracia e Formação Humana. ljui: Editora UNIJUI, 2016.

GEORGEN, Pedro. Formação Humana e Sociedades Plurais. In: MÜHL, Eldon Henrique; DALBOSCO, Claudio Almir; CENCl, Angelo Vitório. (Orgs). Questões Atuais da Educação - Sociedade Complexa, Pensamento Pós-Metafísico, Democracia e Formação Humana.ljui: Editora UNIJUI, 2016.

GONÇALVES, Maria Augusta Salim. Sentir, pensar, agir:corporeidade e educação.3.ed.Campinas:Papirus, 1999.

GONZÁLEZ, Jaime; FENSTERSEIFER, Paulo Evaldo. (orgs.).Dicionário Critico de Educação Física. ljuí: Editora UNIJUI,2006.

LE BRETON, David. Antropologia do Corpo. 4. ed.Petrópolis:Vozes,2016.

Escarificações na adolescência: uma abordagem antropológica. In: Revista Horizontes Antropológicos, ano 16, n.33. Porto Alegre: jan-/jun, 2010.

MARQUES, Mario Osório. Pedagogia: a ciência do educador. ljui: Editora UNIJUI,1996.

MENDES. Maria Isabel Brandão de Souza; NÓBREGA, Therezinha Petruciada.Corpo, Natureza e cultura: Contribuições para a educação. IN: Revista Brasileira de Educação, Set/Nov. n. 27, 2004.

NUSSBAUM , Martha C. Paisajes Del pensamiento - La inteligência de las emociones. Espana: Paidos,2008.

SANT'ANNA, Denise Bernuzzi de. Descobrir o corpo: uma história sem fim IN: Educação \& Realidade, Porto Alegre: FACED/UFRGS, v.25, jul./dez., 2000.

SILVA, Alex Sander da. O Ético, o Estético e a Educação: Uma Relação Inevitável. In: RAJOBAC, Raimundo; BOMBASSARO, Luiz Carlos; GEORGEN, Pedro. Experiência Formativa e Reflexão. Caxias do Sul: EDUCS,2016. 


\section{CRIAR EDUCAÇÃOO}

Revista do Programa de Pós-Graduação em Educação - UNESC

Criar Educação, Criciúma, v. 9, n²2, Edição Especial 2020.- PPGE - UNESC - ISSN 2317-2452

VAZ, Alexandre Fernandez. Violência, corpo e escolarização: apontamentos a partir da Teoria Critica da Sociedade. IN: TABORDA, Marcus Aurélio. (Org.). Educação do corpo na escola Brasileira. Campinas: Autores Associados, 2006.

Recebido junho de 2019

Aprovado junho de 2020 